\title{
Can the impact on health of a government policy designed to create more liveable neighbourhoods be evaluated? An overview of the RESIDential Environment Project
}

\author{
Billie Giles-Corti ${ }^{\mathrm{A}, \mathrm{F}}$, Matthew Knuiman ${ }^{\mathrm{A}}$, \\ Terri J. Pikora ${ }^{\mathrm{A}}$, Kimberly Van Neil ${ }^{\mathrm{B}}$, \\ Anna Timperio', Fiona C. L. Bull ${ }^{\mathrm{D}}$, \\ Trevor Shilton $^{\mathrm{E}}$ and Max Bulsara ${ }^{\mathrm{A}}$ \\ ASchool of Population Health, University of Western Australia \\ ${ }^{\mathrm{B} S c h o o l}$ of Earth and Geographical Sciences, \\ University of Western Australia \\ ${ }^{\mathrm{C}}$ Centre for Physical Activity and Nutrition, \\ School of Exercise and Nutrition Sciences, Deakin University \\ DAdjunct Appointment, School of Population Health, \\ The University of Western Australia and Reader, School of \\ Exercise \& Sports Sciences, Loughborough University \\ ENational Heart Foundation, WA \\ FCorresponding author: Email: billie.giles-corti@uwa.edu.au
}

\begin{abstract}
There is growing interest in the impact of community design on the health of residents. In 1998, the Western Australian Government began a trial of new subdivision design codes (i.e. Liveable Neighbourhoods Community Design Code) aimed at creating pedestrian-friendly neighbourhoods to increase walking, cycling and public transport use. The trial provided a unique opportunity for a natural experiment to evaluate the impact of a government planning policy on residents. Nevertheless, evaluations of this kind present a number of methodological challenges in obtaining the highest quality evidence possible. This paper describes the RESIDential Environment Project's study design and discusses how various methodological challenges were overcome.
\end{abstract}

For decades there has been increasing concern about the unsustainability of post-World War II planning principles adopted in the United States of America (US) and Australia, characterised by segregated land use, disconnected streets, low residential density, limited public transport and local employment and high motor vehicle dependency. ${ }^{1,2}$ However, until relatively recently little attention has been given to the impact of these planning principles on the physical and mental health outcomes of local residents.

A growing number of studies show that urban sprawl, typical of development on the fringe of Australian and US cities, is associated with obesity, hypertension and lower levels of walking, because it encourages driving and discourages active modes of transport, and often results in long commutes. ${ }^{3}$ In Australia, two-thirds of men and onehalf of women are overweight or obese, ${ }^{4}$ as are between 19 and $23 \%$ of Australian children and adolescents. ${ }^{5}$ Moreover, only about one-half of Australian adults are sufficiently active to benefit their health (i.e. undertaking as little as 30 minutes of daily moderate physical activity), and levels of physical activity appear to be declining. 6,7 While a multitude of factors are implicated in these trends, there is growing international attention on the contribution made by so-called 'obesogenic' environments, ${ }^{8,9}$ including urban development, which discourage physical activity.

This paper contributes to the methodological literature. It describes the design of an evaluation of a state government land subdivision design code which aims to encourage more walking, cycling and public transport use by local residents. It begins with a background to the development of the Liveable Neighbourhoods Community Design Code, before describing the evaluation's study design. It then goes on to discuss methodological issues that have arisen for consideration in future natural experiments of this type.

\section{New Urbanism}

One response to concerns about the unsustainability of urban sprawl has been a new approach to planning known as 'New Urbanism', which aims to create more pedestrianfriendly neighbourhoods. ${ }^{7,10-12}$ Based on traditional planning principles, neighbourhoods designed according to these principles have connected street networks, higher density of development, mixed-use zoning (i.e. a combination of commercial and residential development) and access to public transport. ${ }^{13,14}$ A study from the United Kingdom found that traditional neighbourhoods generated 
about $57 \%$ fewer vehicle miles, ${ }^{15}$ while a small study by Saelens and colleagues ${ }^{16}$ found that 'high walkable' neighbourhoods in the US generated more weekly transport walking trips than 'low walkable' neighbourhoods (3.1 compared with 1.4 walking trips per week). There is growing cross-sectional evidence that community design policy is an effective tool for increasing walking, cycling and public transport use, thereby reducing driving and improving air quality. ${ }^{17,18}$

In Western Australia, the state government is responsible for subdivision policy (Western Australian Planning Commission) and assessment of all subdivision proposals (Department for Planning \& Infrastructure). In 1998, it began a trial of the Liveable Neighbourhoods Community Design Code, ${ }^{19}$ which is based on New Urbanism principles. By creating more 'liveable' neighbourhoods with greater access to services and more efficient use of land, it is hoped that car use will be reduced and walking, cycling and public transport use will be increased. ${ }^{7}$

\section{The RESIDential Environment Project}

The extent to which a new government policy can influence active transport behaviour is the subject of the Healthway-funded RESIDential Environment project (known as RESIDE). Commencing in 2003, the principal aim of RESIDE is to study the impact of the state government's Liveable Neighbourhoods Community Design Code on the walking, cycling and public transport use behaviour of local residents. RESIDE is a longitudinal study of people building homes in new housing developments, some of which are designed according to the Liveable Neighbourhoods Community Design Code. The study was developed in response the need for causal evidence on the relationship between the built form and physical activity. ${ }^{3,18}$ Hence, its longitudinal design will enable the study of selection: do individuals choose environments that match their preferred behaviour or does the environment shape their behaviour?

\section{Study design}

RESIDE involves three data collections over five years with each collection undertaken in the same season. The timing of these collections is:

(1) baseline - before participants moved into their new home;

(2) 1 st follow-up - 12 months after moving into their new home; and

(3) 2nd follow-up - two years later.

On each occasion, participants complete a self-completion questionnaire and wear a Yamix Digi-walker pedometer (SW-200-024) for seven days. The pedometer is a small motion sensor worn on the belt that measures the number of steps taken. It provides an objective measure of overall physical activity behaviour irrespective of the type and where it takes place.

\section{Selection of housing developments}

All structure plans for new housing developments in Western Australia are approved by the Department for Planning and Infrastructure. During the Liveable Neighbourhood trial period, structure plans developed using the Liveable Neighbourhoods Community Design Code were subjected to a separate review process. The key elements of conventional and liveable neighbourhoods as defined by Jones ${ }^{12}$ are presented in Table 1. Developments with many but not all of the Liveable Neighbourhood elements were assessed as 'hybrid' developments.

Accordingly, 18 of the 74 RESIDE developments were assessed as Liveable Neighbourhood developments, 45 as conventional developments and 11 as 'hybrid' developments. All Liveable Neighbourhood developments and 'hybrid' developments that sold land for housing during the recruitment period were included in the study areas. Attempts were made to match the conventional developments to the Liveable Neighbourhood developments and 'hybrid' developments in terms of stage of development, lot value and proximity to the ocean.

\section{Selection of participants}

Participants were selected from households that had purchased land in the 74 housing developments. Recruitment

Table 1. Key elements of conventional and Liveable Neighbourhoods

\begin{tabular}{|c|c|c|}
\hline Characteristic & Conventional & Liveable Neighbourhoods \\
\hline Land use diversity & $\begin{array}{l}\text { Single use; predominantly residential, with } \\
\text { designated areas of clustered retail; } \\
\text { segregated use base }\end{array}$ & $\begin{array}{l}\text { Integrated mixed-use; neighbourhood based with } \\
\text { integrated residential, retail, commercial and } \\
\text { service industrial }\end{array}$ \\
\hline $\begin{array}{l}\text { Street pattern } \\
\text { and type }\end{array}$ & $\begin{array}{l}\text { Curvilinear and hierarchical from district } \\
\text { distributors, to collectors, to access streets, to } \\
\text { cul-de-sac; traffic collected and channelled }\end{array}$ & $\begin{array}{l}\text { Inter-connected network; a flatter hierarchy of types; } \\
\text { traffic dispersed }\end{array}$ \\
\hline Dominant retail type & Regional 'big box' shopping centres, chain stores & Neighbourhood independent retailers \\
\hline $\begin{array}{l}\text { Dominant planning } \\
\text { objective }\end{array}$ & Create comfortable housing & $\begin{array}{l}\text { Create community; create affordable housing; } \\
\text { jobs containment }\end{array}$ \\
\hline
\end{tabular}


occurred in waves every six months from September 2003 to March 2005. To be eligible, participants needed to be proficient in English; 18 years or over; planning to move into their new house by December 2005; and willing to complete surveys and wear a pedometer for seven days on three separate occasions over four years. The Water Corporation, the state water agency, wrote to all its customers building houses in the study areas inviting their participation and requesting return of a reply-paid card if they were ineligible or did not want to be contacted by the study team $(n=10193)$. The names and addresses of people who did not return the card within 10-14 days were matched to the electronic white pages and telephoned by trained interviewers at the School of Population Health's Survey Research Centre $(n=5286)$ and screened for eligibility. Those who could not be contacted by telephone after six follow-up calls and for whom no telephone contact details were available $(n=3862)$ were invited to participate by letter. Three follow-up letters were sent. All participants received written information about the study and provided written consent before completing the baseline questionnaire.

\section{Measures}

RESIDE is an ecological study, ${ }^{20-23}$ in that it will measure multiple levels of influence on behaviour. RESIDE study participants will complete comprehensive questionnaires that measure a range of individual-level (e.g. demographic and health-related characteristics, attitudes, perceptions), social environmental (e.g. social support for physical activity) and physical environmental (e.g. perceptions of the local neighbourhood) factors that might influence participation in active modes of transport. To complement the objective measure of overall behaviour using pedometers, self-reported physical activity is also being measured using the Neighbourhood Physical Activity Questionnaire. This questionnaire measures the frequency and duration of usual walking and cycling undertaken within and outside the neighbourhood as well as other moderate- and vigorous-intensity physical activity. ${ }^{24}$ The tool was specifically designed for use in longitudinal studies of the impact of urban design on physical activity and makes it possible to differentiate walking and cycling behaviours that take place within and outside the neighbourhood. This allows the impact of the government's Liveable Neighbourhoods Community Design Code on behaviour undertaken locally to be studied.

In addition to individual-level data, a key objective of RESIDE is to develop objective measures of the physical environment surrounding the study participants' homes (both at baseline addresses and in new neighbourhoods), using Geographic Information System data. A walkability index based on that developed by Frank and colleagues ${ }^{25,26}$ has been developed for this study by Learnihan. ${ }^{27}$

\section{RESIDE study participants}

RESIDE includes 1813 study participants who have returned completed baseline questionnaires $(33.4 \%$ response rate overall). Overall, $40.5 \%$ of the RESIDE participants are male and the average age at baseline was 40 years (SD 11.9). Given that study participants are home buyers, not surprisingly only one-quarter have a household income of less than $\$ 50000$ per annum (24.5\%). At baseline, there was no difference between the transport-related or recreational walking undertaken by the study participants living in the different types of neighbourhoods. ${ }^{28}$ Only $20 \%$ of the total walking undertaken at baseline was transport-related walking and undertaken within the neighbourhood. Given that the Liveable Neighbourhoods Community Design Code aims to increase local walking, it will be important to monitor any increase in the amount of transport-related walking. The baseline data collection was completed in December 2005, and first follow-up questionnaires were completed by December 2006. Distribution of the second follow-up questionnaire commenced in September 2006 and is due for completion by December 2008.

\section{Discussion}

There is growing recognition that neighbourhood design can influence both health and environmental outcomes, but there is limited causal evidence of its impact. RESIDE seeks to redress this gap by prospectively evaluating the impact of a new government planning policy on local residents. Its longitudinal design will contribute to evidence about whether neighbourhood design simply facilitates the behaviours of those already predisposed to use active forms of transport or whether it can be used as a policy tool to change behaviour. Importantly, the collection of data on multiple levels of influence of behaviour (i.e. individual-level, social environmental and physical environmental) allows the study of the impact of neighbourhood design relative to individual-level attitudes and social norms. These data will inform future educational and policy interventions.

There are synergies between health, sustainability and planning agendas, as each sector attempts to encourage active modes of transport. While the objectives of these agendas differ markedly (i.e. to produce health, environmental or traffic management outcomes), the strategies required to achieve these policy outcomes are similar. ${ }^{22}$ Thus, in this area there are unprecedented opportunities for collaborative effort across disciplines and sectors to devise multiple-level interventions, transdisciplinary approaches to research ${ }^{29}$ and advocacy campaigns designed to hasten policy changes to redress these problems.

The Liveable Neighbourhoods Community Design Code represents an attempt by a state government to create pedestrian-friendly neighbourhoods and is receiving 
national and international attention as a best-practice policy. Given the potential for government policy to create supportive infrastructure that can influence behaviour and produce health and environmental outcomes, it is important to monitor positive (and unintended negative) outcomes.

RESIDE involves a collaborative study with the policy makers (Department of Planning and Infrastructure and the Western Australia Planning Commission) and will prospectively monitor the impact of this policy on the health and social outcomes of local residents. It seeks to overcome a number of methodological challenges in studying the impact of community design on various health behaviour outcomes.

First, it is longitudinal and surveys residents before they move into their new homes. This will allow study selection to be studied. Fortunately, at baseline there were few differences between those moving into Liveable Neighbourhood developments and other types of neighbourhoods in terms of their demographic or behavioral characteristics. ${ }^{28}$ Second, RESIDE included all Liveable Neighbourhood and hybrid developments being built during the study period, and where possible, it sought to match these with conventional developments on the basis of distance from the ocean, stage of development and price. Apart from attempting to control for socioeconomic status and quality of access to facilities and services, there was also an attempt to avoid a 'coastal effect' which suggests that those living in coastal locations are more physically active than others. ${ }^{30}$ Third, the study collects both self-report and objective measures of walking, cycling and overall physical activity. Fourth, the self-report measures are behaviour and context-specific ${ }^{31}$ with study participants reporting separately about recreational and transport-related walking and cycling behaviours undertaken within, and outside, the neighbourhood. ${ }^{24}$ Fifth, the behavioural questionnaire uses 'usual' behaviour rather than behaviour in the last seven days or a diary. We believe that usual behaviour will be a more stable measure, which is preferable in a longitudinal study. Sixth, the study has been designed to take into account seasonal effects and seeks to resurvey study participants in the same season that they completed the baseline survey. Seventh, it includes both perceptions of the neighbourhood and objective measures of the neighbourhood and has a consistent definition of what constitutes a 'neighbourhood' in both the questionnaires completed by study participants and the objective measures of the neighbourhood. Finally, using a modified version of a method proposed by Dillman, ${ }^{32}$ the study attempts to maximise the response rate by incorporating a comprehensive system to contact and re-contact study participants during the recruitment and follow-up phases.
Despite attempts to overcome methodological challenges, the study has a number of limitations. It is restricted to people building homes in new housing estates, and, therefore, is not representative of a general population sample, nor does it include lower socioeconomic groups. Despite attempting to maximise the response rate from the outset, the initial response rate was only $33 \%$. Undoubtedly, this was partly due to the fact that study participants were made aware from the outset about the study requirements (as was required by the University's Human Ethics Committee). Not only did this involve an extensive questionnaire, but it also required the study participants to wear a pedometer for a week and to complete a pedometer diary.

Regardless of these limitations, at this stage, RESIDE is unique internationally. Moreover, studies of this type are important to inform the development of future policy and practice with the aim of optimising neighbourhood designs to produce health, planning and sustainability outcomes.

\section{Acknowledgements}

Funding received from the Western Australian Health Promotion Foundation (Healthway) and the Australian Research Council is gratefully acknowledged. The first author is supported by a NHMRC/NHF Career Development Award (Grant No. 254688). Anna Timperio is supported by a VicHealth Public Health Fellowship (2004 0536). Editorial assistance provided by Sarah French is gratefully acknowledged.

\section{References}

1. Newman P, Kenworthy J. Sustainability and cities: overcoming automobile dependence: an international sourcebook. Aldershot, England: Gower, 1989.

2. Newman PWG, Kenworthy JR. Sustainable urban form: the big picture. In: Williams K, Burton E, Jenks M, editors. Achieving Sustainable Urban Form. London: E and FN Spon, 2000. pp. 109-20.

3. Ewing R, Schmid T, Killingsworth R, Zlot A, Raudenbush S. Relationship between urban sprawl and physical activity, obesity and morbidity. Am J Health Promot 2003; 18(1): $47-57$.

4. NHMRC. Acting on Australia's weight. Canberra: Comm. of Aust, 1997.

5. Booth MLWM, Armstrong T, Chey T, Hesketh K, Mathur S. The epidemiology of overweight and obesity among Australian children and adolescents 1995-97. Aust N Z J Pub Health 2001; 25(2): 162-9.

6. Armstrong T, Bauman A, Davies J. Physical activity patterns of Australian adults. Results of the 1999 National PA Survey. Canberra: AIHW, 2000.

7. McCormack G, Milligan R, Giles-Corti B, Clarkson J. Physical activity levels of Western Australian adults 2002: results from the adult physical activity survey. Perth: Western Australian Government, 2003.

8. Swinburn B, Egger G, Raza F. Dissecting obesogenic environments: the development and application of a framework for 
identifying and prioritising environmental interventions for obesity. Prev Med 1999; 29(6): 563-70.

doi:10.1006/pmed.1999.0585

9. Hill J, Wyatt H, Reed G, Peters J. Obesity and the environment: Where do we go from here? Science 2003; 299: 853-5. doi:10.1126/science. 1079857

10. Calthorpe P. The next American metropolis: ecology and urban form. New Jersey: Princeton Architectural Press, 1993.

11. Katz P. The new urbanism: toward an architecture of community. New York: McGraw Hill, 1994.

12. Jones E. Liveable Neighbourhoods. World Transp Policy Pract 2001; 7(2): 38-43.

13. Dutton J. American New Urbanism: Re-forming the suburban metropolis. London: Skira; 2001.

14. Hall K, Giles-Corti B. Complementary therapies and the general practitioner. A survey of Perth GPs. Aust Fam Physician 2000; 29(6): 602-6.

15. Chellman R. City of Portsmith. Traffic/Trip Generation Study. New Hampshire: White Mountain Survey Inc., 1991.

16. Saelens BE, Sallis JF, Black JB, Chen D. Neighborhood-based differences in physical activity: An environment scale evaluation. Am J Public Health 2003; 93(9): 1552-8.

17. Transportation Research Board. Does the built environment influence physical activity? Examining the evidence. Washinton, DC: TRB, 2005.

18. Handy S, Cao XY, Mokhtarian P. Correlation or causality between the built environment and travel behavior? Evidence from Northern California. Transport Res D-Tr E 2005; 10(6): 427-44. doi:10.1016/j.trd.2005.05.002

19. Western Australian Planning Commission. Liveable Neighbourhoods. Perth: Western Australian Planning Commission, 2000.

20. von Bertalanffy L. General system theory. Foundations, development, applications. New York: George Braziller, 1968.

21. Stokols D. Translating social ecological theory into guidelines for community health promotion. Am J Health Promot 1996; 10(4): 282-98.

22. Sallis JF, Cervero RB, Ascher W, Henderson KA, Kraft MK, Kerr J. An ecological approach to creating active living communities. Annu Rev Public Health 2006; 27: 297-322. doi:10.1146/annurev.publhealth.27.021405.102100
23. McLeroy KR, Steckler AB, Simons-Morton B, Goodman RM, Gottlieb N, Burdine JN. Social science theory in health education: time for a new model? Health Educ Res 1993; 8: 305-12. doi:10.1093/her/8.3.313

24. Giles-Corti B, Timperio A, Cutt H, Pikora TJ, Bull FC, Knuiman $\mathrm{M}$ et al. Development of a reliable measure of walking within and outside the local neighborhood: RESIDE's Neighborhood Physical Activity Questionnaire. Prev Med 2006; 42: 455-9. doi:10.1016/j.ypmed.2006.01.019

25. Frank LD, Andresen MA, Schmid TL. Obesity relationships with community design, physical activity, and time spent in cars. Am J Prev Med 2004; 27(2): 87-96. doi:10.1016/j.amepre.2004.04.011

26. Leslie E, Saelens B, Frank L, Owen N, Bauman A, Coffee N et al. Residents' perceptions of walkability attributes in objectively different neighbourhoods: a pilot study. Health Place 2005; 11(3): 227-36. doi:10.1016/j.healthplace. 2004.05.005

27. Learnihan V. The physical environment as an influence of walking in the neighbourhood: Objective measurement and validation. Perth: The University of Western Australia, 2006.

28. Giles-Corti B, Knuiman M, Timperio A, Van Niel K, Pikora T, Bull $\mathrm{F}$ et al. Evaluation of the implementation of a stategovernment community design policy aimed at increasing local walking: Design issues and baseline results from RESIDE, Perth Western Australia. Prev Med In press.

29. Sallis JF, Frank LD, Saelens BE, Kraft MK. Active transportation and physical activity: opportunities for collaboration on transportation and public opportunities health research. Transport Res A-Pol. 2004; 38(4): 249-68. doi:10.1016/j.tra.2003.11.003

30. Bauman A, Smith B, Stoker L, Bellew B, Booth M. Geographical influences upon physical activity participation: evidence of a 'coastal effect'. Aust N Z J Public Health 1999; 23(3): 322-4.

31. Giles-Corti B, Timperio A, Bull F, Pikora T. Understanding Physical Activity Environmental Correlates: Increased Specificity for Ecological Models. Exerc Sport Sci Rev 2005; 33(4): 175-81. doi:10.1097/00003677-200510000-00005

32. Dillman DA. Mail and internet surveys. The Tailored Design Method. New York: John Wiley \& Sons Inc., 2000. 